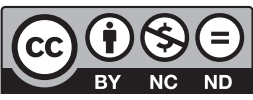

Estudos Teológicos foi licenciado com uma Licença Creative Commons Atribuição - NãoComercial - SemDerivados 3.0 Não Adaptada

http://dx.doi.org/10.22351/et.v60i2.4048

\title{
"NoS VEMOS ON-LINE": DIFERENTES VOZES SOBRE A BUSCA POR DEUS NO CENÁRIO PANDÊMICO BRASILEIRO ${ }^{1}$
}

\author{
"We see us on-line": \\ different voices on the search for God \\ in the Brazilian pandemic scenario
}

\begin{abstract}
Marlon Machado Oliveira Rio
Resumo: O cenário de pandemia global do atual coronavírus (Covid-19) é marcado por constantes transformações, com massivo uso de tecnologias digitais em diferentes esferas da sociedade. Isso ocorre similarmente no cenário teológico, uma vez que a aglomeração de pessoas tornou-se limitada. No ínterim das variadas práticas culturais contemporâneas nasce também uma teologia no espectro tecnológico, denominada recentemente ciberteologia. $\mathrm{O}$ presente trabalho, sob o viés de entendimento da Teologia Prática, visa compreender o uso das tecnologias digitais na manutenção da fé e visualizar as potencialidades das tecnologias para o fortalecimento do contato com o transcendente em um momento no qual a igreja está isolada, mas interconectada dentro da atmosfera espiritual e digital. Por meio da análise de uma matéria disponibilizada pela BBC Brasil [British Broadcasting Corporation], descrevem-se as ações de diferentes líderes religiosos no contexto pandêmico quanto à (não) realização de cultos presenciais no cenário pandêmico. Os resultados apontam preliminarmente que alguns líderes mantiveram a realização dos cultos majoritariamente no modo presencial, apesar de todos os problemas de saúde que tal atitude poderia acarretar, enquanto outros oportunizaram novas maneiras de se buscar Deus dentro do ciberespaço, ampliando-se, destarte, a atuação da igreja para outros lugares antes possivelmente não alcançados.
\end{abstract}

Palavras-chave: Tecnologias digitais. Teologia Prática. Pandemia. Ciberteologia.

Abstract: The global pandemic scenario of the current Coronavirus (Covid-19) is marked by constant changes, with massive use of digital technologies in different instances of society. This occurs similarly in the theological scenario, since the gathering of people has become limited. In the midst of the varied contemporary cultural practices, a theology in the technological spectrum has been born, recently

1 O artigo foi recebido em 04 de julho de 2020 e aprovado em 15 de setembro de 2020 com base nas avaliações dos pareceristas ad hoc.

2 Doutor. PUC-RS. E-mail: marlon.rio@acad.pucrs.br 
named cybertheology. The present work, under the framework of understanding of the Practical Theology, aims to understand the use of digital technologies to keep the faith and visualize the potentialities of technologies as to strengthening contact with the transcendent at a time when the church is isolated, but interconnected within the spiritual and digital atmosphere. Through the analysis of an article published by BBC Brazil [British Broadcasting Corporation], the actions of different religious leaders in the pandemic context regarding the (non) realization of face-to-face services in the pandemic scenario are described. The results point out preliminarily that some leaders kept the religious services mostly in person, despite all the health problems that such an attitude could bring about, while other ones provided new ways to seek God within the cyberspace, thus expanding the actions taken by the church to other places which were previously not possibly reached.

Keywords: Digital technologies. Practical Theology. Pandemic. Cybertheology.

\section{Introdução}

A transitoriedade pela qual circulam nossas atividades cotidianas pode trazer otimismo para aqueles que sonham com a inovação ou angústia para aqueles que não se ajustam aos diferentes movimentos advindos pelo uso de novas tecnologias. ${ }^{3} \mathrm{Da}$ mesma maneira que as tecnologias conseguiram transformar as diferentes relações entre os seres humanos, essas também demonstraram seu impacto na área espiritual desses, haja vista que diferentes modos de se ter contato com aquilo que transcende sua realidade humana são também relatados no mundo virtual. ${ }^{4}$ Dentro dessa nova cibercultura $^{5}$ nasce também uma teologia diferente, denominada atualmente ciberteologia. ${ }^{6}$ Essa, por sua vez, leva consigo as diferentes manifestações do divino e das maneiras como os seres humanos expressam, comunicam e se comportam mediante sua fé na realidade digital.

Conforme aponta Oliveira ${ }^{7}$, a atual pandemia do coronavírus tem trazido grandes problemas para o mundo e a própria realidade brasileira. $\mathrm{O}$ atual nome coronavírus tem sua nomenclatura comum Covid-19, em que CO significa corona, VI denota vírus e D representa doença, o número 19 indica o ano de sua aparição, em 2019. O vírus apresenta grandes riscos à saúde, sentidos principalmente pela população acima de 60 anos. Conforme aponta $\operatorname{Lima}^{8}$, o Covid-19 faz parte de uma grande família viral, já conhecida desde meados de 1960, a qual pode causar infecções respiratórias em

\footnotetext{
LEITCH, Vincent. Postmodern Theory of Technology: Agendas. Symploke, v. 12, n. 1, p. 209-215, 2004.

4 THEOBALD, Cristoph. A exortação apostólica Evangelii Gaudium. Cadernos Teologia Pública, ed. 104, v. 12, 2016.

5 LÉVY, Pierre. Cibercultura. São Paulo: Editora 34, 1999. p. 220.

6 SPADARO, Antonio. Ciberteologia: pensar o Cristianismo em tempos de rede. São Paulo: Paulinas, 2012.

7 OLIVEIRA, Márcio Divino. Cuidado pastoral da igreja em tempos de pandemia: Covid-19. Revista Caminhando, v. 25, n. 1, p. 257-276, 2020.

8 TAVARES, Cássia Quelho. Dimensões do cuidado na perspectiva da espiritualidade durante a pandemia pelo novo coronavírus (COVID-19). J Health NPEPS, v. 5, n. 1, p. 1-4, 2020.
} 
seres humanos e animais. As infecções causadas por vírus como o Covid-19 podem ocasionar doenças respiratórias leves e moderadas, similares a um simples resfriado. No entanto, é possível também ocorrer doenças graves, que podem ter um grande impacto na saúde pública, como a Mers (Síndrome Respiratória do Oriente Médio), encontrada em 2012, e a Sars (Síndrome Respiratória Aguda Grave), a qual foi identificada em 2002. O vírus é de alto contágio e pode ser transmitido facilmente, em especial em lugares com alta movimentação e concentração humanas. ${ }^{9}$ Locais como os templos religiosos põem, portanto, a saúde dos fiéis em grande risco.

Levando-se em conta as drásticas mudanças que o atual coronavírus trouxe para o mundo nesses últimos meses ${ }^{10}$, o presente artigo torna-se importante ao buscar compreender de maneira panorâmica como a busca por Deus é praticada diante do cenário contemporâneo de pandemia. Esse tema se torna relevante uma vez que muitos templos religiosos possuem suas atividades majoritariamente suspensas por medidas de proteção a seus fiéis. Destarte, por um viés da Teologia Prática, examina-se essencialmente aqui a relação entre a igreja e seus contextos vividos em diversos loci sociais. ${ }^{11}$ Intenta-se também compreender a busca pelo divino neste novo contexto virtualmente construído.

Para tanto, o trabalho organiza-se do seguinte modo: a primeira seção abarca sucintamente os estudos realizados na área de tecnologias digitais, vistas por elementos axiológicos da sociologia, filosofia e da religião, as quais demonstram as contingentes transformações que as tecnologias trouxeram ao mundo ${ }^{12}$ como um todo. A segunda seção, de maneira a melhor delimitar a Teologia Prática, elenca também sucintamente o que se denomina atualmente ciberteologia ${ }^{13}$. Apresenta-se, para tanto, a relevância dessa para um melhor entendimento do que ocorre presentemente diante dos desafios trazidos pela Covid-19, com foco nas modificações dentro do cenário religioso contemporâneo.

Por um viés bibliográfico e de abordagem qualitativa ${ }^{14}$, este trabalho apresenta, na terceira seção, os aspectos metodológicos do presente artigo. O objeto de pesquisa será uma notícia do website BBC Brasil [British Broadcasting Corporation], a qual relata as diferentes práticas de diferentes religiões no cenário pandêmico e como os seus dissimilares líderes estão lidando com essa situação. Posteriormente, com a análise e discussão dos dados, são trazidas conclusões preliminares e pertinentes de

9 LIMA, Claudio Marcio. Informações sobre o novo coronavírus (COVID-19). Radiol Bras, São Paulo, v. 53, n. 2, p. 5-6, 2020.

10 ZHOU, Longjun et al. 'School's Out, But Class' On', The Largest Online Education in the World Today: Taking China's Practical Exploration During The COVID-19 Epidemic Prevention and Control as an Example of Best Evidence. Chinese Education, v. 4, n. 2, p. 501-519, 2020.

11 DESCHNER, John. Preface to Practical Theology. J. Arthur Heck Lectures, United Theological Seminary, p. 21-22 de abril 1981. Manuscrito não publicado.

12 SINGH, Paul. Use of science and technology as a tool of social change. International Journal of Academic Research and Development. v. 2, n. 1, p. 124-127, 2017.

13 SPADARO, Antonio. Spiritualità ed Elementi per una Teologia della Comunicazione in Rete. In: Seminário de Comunicação para os Bispos do Brasil (SECOBB), 2011, Rio de Janeiro. Anais. Brasília: CNBB, 2011.

14 CASTELLS, Manuel. A sociedade em rede. São Paulo: Paz e Terra, 2005. p. 190. 
como se encontram as práticas de fé no atual cenário de pandemia. Conclusões são sumariamente trazidas, de maneira a estimular pesquisas futuras concernentes às áreas da filosofia da tecnologia e da ciberteologia, haja vista que o mundo digital possivelmente se fará exponencialmente mais presente e diferente na vida de todo ser humano nos próximos anos.

Passemos à primeira seção deste artigo, a qual lidará com as nuances atuais das tecnologias digitais no mundo contemporâneo.

\section{Tecnologias digitais, comunicação e contemporaneidade}

Vive-se atualmente um período de velozes transformações, com visão à interação, à pluralidade, à diversidade e à inovação. ${ }^{15}$ Hoje se pode lidar com a realidade virtual, a qual, antes prevista por Pierre Lévy ${ }^{16}$, nos faria entrar em uma nova maneira de se produzir cultura. Para Lévy, vive-se presentemente a época da cibercultura, na qual a cultura da comunicação, do encontro, da troca de opiniões, do diálogo e de amizades encontra-se (preponderantemente) em loci virtuais.

A cibercultura é composta de técnicas, atitudes, práticas sociais diversificadas, com diferentes modos de pensar e de valores dissimilares dentro do mundo da internet. Dentro da cibercultura é criado o ciberespaço, o qual agrupa não apenas a infraestrutura material da comunicação digital, mas similarmente o universo oceânico de informações nele arraigados, bem como os seres humanos que trafegam e se alimentam nessa nova instância. Conforme aponta Joana Puntel ${ }^{17}$, o ser humano está em uma época de mudanças, com evidentes sinais de transição. Dentro desse período, o ser humano passa por uma sensação de vazio, com uma falta de senso e de normas, com incertezas e de crises recorrentes. Nos tempos atuais vive-se irreversivelmente uma mutação cultural.

Vive-se similarmente hoje a Era da Comunicação Midiática, na qual realidades on-line e off-line se fundem, com influência em todos os setores da sociedade. Destarte, há uma difusão cultural ${ }^{18}$ nunca antes vista, na qual diferentes culturas antes isoladas e experimentadas apenas dentro de um mesmo contexto são compartilhadas e vividas mesmo longe de seu lócus original. ${ }^{19}$ Há a presença de um novo homo sapiens, denominado homo digitalis. Para tanto, o conhecido cogito cartesiano parece ser transposto para a ideia de "Estou on-line, logo existo".

\footnotetext{
15 ANDREOLLA, Jurema. A fé cristã na era digital: Diálogo entre a revelação na tecnologia de Bruno Forte e a experiência religiosa na Internet. 2012. Dissertação (Mestrado em Teologia) - Pontifícia Universidade Católica do Rio Grande do Sul (PUCRS), Porto Alegre, 2012. p. 103.

16 LÉVY, 1999, p. 124.

17 PUNTEL, Joana Teresinha; SBARDELOTTO, Moisés. Da reforma histórica à "reforma digital": desafios teológicos contemporâneos. Estudos Teológicos, São Leopoldo, v. 57, n. 2, p. 350-364, 2017.

18 SINGH, 2017, p. 125.

19 ELLUL, Jacques. La technique ou l'enjeu du siècle. Paris: Économica, 2008. p. 145.
} 
Dentro dessas diferentes maneiras de se organizar a sociedade, surgem dois grandes grupos que, paulatinamente, parecem se diferenciar a cada dia. Esses são os nativos digitais e os imigrantes digitais. ${ }^{20}$ Os imigrantes digitais emblemam aqueles que nasceram antes do advento da Internet, viram seu crescimento e hoje estão convivendo com essa. Para muitos que viveram antes da Internet, fazer uso de diferentes aplicativos e tecnologias digitais é um desafio e uma maneira diferente de se comportar. Entendidas aqui como todo e qualquer suporte material e digital que estabeleçam entre si uma conexão entre dois pontos ou até mesmo mais, com a finalidade de transmitir e/ou receber diferentes informações ${ }^{21}$, as mídias e tecnologias digitais implicam uma nova maneira de se mover dentro do mundo.

Para os nativos digitais, os quais nasceram durante e após a década de 1990, esses aparentemente já se habituaram a empregar as tecnologias para diferentes atividades diárias. Estão hiperconectados e possivelmente não conseguem imaginar suas vidas sem a Internet ou sem seu smartphone. ${ }^{22}$ Os especialistas afirmam que os nativos digitais podem ser extremamente sociais ou individualistas (o que irá depender muito do quanto esses sabem usar as diferentes tecnologias - para alcançar ou se distanciar de outras pessoas). Eles também são conhecidos por serem cinestésicos, sentindo-se melhores para trabalhar e interagir em lugares e com ferramentas coloridas, multifuncionais (assim como eles são) e multissemióticas. Os nativos digitais são pessoas extremamente desafiáveis. Isso significa que eles amam participar de tarefas que os engajem e os desafiem a ser melhores do que os outros, de maneira que suas motivações também sejam elevadas para aprendizagens mais profundamente coletivas. ${ }^{23}$

Os nativos digitais também possuem grandes dificuldades concernentes à sua área emocional. Isso se deve ao fato de eles enfrentarem uma grande carência e falta de inteligência emocional ${ }^{24}$, vivendo sob uma rotina gradativamente mais estressante e repleta de idiossincrasias diárias. Mais constantes são os episódios relacionados a casos de depressão, crises de ansiedade, doenças psicossomáticas, cyberbullying, pressões exacerbadas de pais, professores e colegas de aula, os quais desembocam, concomitantemente, em episódios de conflitos internos jamais vistos. ${ }^{25}$

Como a igreja pode interagir e possivelmente intervir na diminuição de tais efeitos negativos, diante de um cenário de mudanças constantemente mais velozes do que a época da Reforma Protestante ${ }^{26}$ Como a igreja pode lidar dentro da Reforma da Informação, dentro de uma Gesellschaft (termo da filosofia alemã para designar sociedade) que se tornou verdadeiramente uma virtuelle Gemeinschaft (comunidade

\footnotetext{
${ }^{20}$ PRENSKY, Marc. Teaching digital natives: partnering for real learning. Corwin Edition, 2010. p. 260.

${ }^{21}$ FEENBERG, Andrew. Transforming Technology: a critical theory revisited. New York: Oxford University Press, 2002. p. 140.

22 PRENSKY, 2010, p. 127.

23 PRENSKY, 2010, p. 120.

24 BERROCAL, Pablo; RUIZ, Desirée. Emotional Intelligence in Education. Electronic Journal of Research in Educational Psychology, v. 6, n. 15, n. 2, p. 421-436, 2008.

${ }^{25}$ LITTO, Frederico; FORMIGA, Marcos (Ed.). Educação a distância: o estado da arte. 2. ed. São Paulo: Pearson, 2012.

26 PUNTEL, Joana Teresinha. Comunicação: diálogo dos saberes na cultura midiática. São Paulo: Paulinas, 2010.
} 
virtual internamente unida - na filosofia alemã), cada vez mais interconectada? ${ }^{27}$ Adicionalmente, como lidar com tais conflitos e heterogeneidades em um contexto como o da atual Covid-19, o qual também ocasiona diferentes transformações em toda a brasilianische Gemeinschaft (comunidade brasileira)? Esse é um dos prismas centrais da próxima seção.

\section{As adaptações da igreja perante a nova era tecnológica}

Conforme aponta Spadaro ${ }^{28}$, o desafio da igreja atual não está no fato dela usar bem a rede de informações, mas em como viver bem o tempo da rede. Isto é, a preocupação maior não está mais centrada na utilização, mas na vivência da igreja dentro do ciberespaço. De ferramenta a tecnologia possibilita a criação de uma atmosfera cibernética na qual a fé e o transcendente se encontram. A Internet é, sem dúvida, um novo contexto existencial, não apenas um lugar específico no qual alguém entra em algum momento e do qual se sai para entrar novamente na vida off-line. É um novo modo de se estar no mundo.

Imagens ou vídeos com forte apelo emocional podem, infelizmente, estar mais

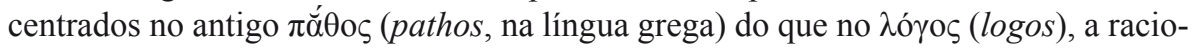
nalidade e organização intrínseca da fé cristã. ${ }^{29}$ Isso pode levar a um maior enfoque naquilo que emociona, naquilo que diverte, sensibiliza ou comove, do que naquilo que pode ser cognitivamente compreendido e compartilhado por diferentes pessoas e trazer uma mudança factual de vida. Para tanto, o है $\theta 0 \varsigma$ (ethos) na era digital, isto é, a maneira como proceder tanto em atos como cristão, inclui, deste modo, a evangelização, a preservação e o compartilhamento da fé e da verdade cristã. Em tempos midiáticos esse mesmo ethos pode ser drasticamente corrompido a fim de "se alcançar a todos". Com isso há o perigo de se perder a essência da mensagem cristã em uma tentativa frenética de se englobar todos quanto for possível. ${ }^{30}$

Um fenômeno fortemente estudado diante das atuais mudanças do acesso a diferentes crenças religiosas é o da privatização da religião ${ }^{31}$, a qual é compreendida dentro do crescente pluralismo religioso. Os antigos monopólios religiosos encontram-se enfraquecidos com a abertura de um bem de consumo vital para qualquer sociedade moderna: a própria fé. Com tal abertura, as crenças e práticas religiosas adotam um escopo menos absolutista e mais personalizado. Martelli ${ }^{32}$ afirma que o indivíduo contemporâneo pode comandar sua religiosidade, não sendo mais dependente das tradições culturais, familiares ou eclesiásticas, mas de suas próprias esco-

27 FEENBERG, 2002, p. 75.

28 SPADARO, 2012, p. 30.

${ }^{29}$ COPPE, Moisés Abdon. Ethos Mundial e Nova Criação: um debate necessário para a salvaguarda do planeta Terra. Revista Caminhando, v. 19, n. 1, p. 97-108, 2014.

30 ANDREOLLA, 2012, p. 80.

31 LIBÂNIO, João Batista. A religião no início do milênio. São Paulo: Loyola, 2002. p. 240.

32 MARTELLI, Stefano. A religião na sociedade pós-moderna: entre secularização e dessecularização. São Paulo: Paulinas, 1995. p. 250. 
lhas. Berger ${ }^{33}$ e Feitosa ${ }^{34}$ apontam coletivamente que da mesma maneira que a cidade moderna apresenta diferentes escolhas plurais para o novo residente lá presente, a escolha da fé que o indivíduo seguirá poderá ser uma questão de escolha feita com base nos comodismos, privilégios ou até mesmo nas vantagens trazidas pelo templo/ mercado religioso. Com o aumento de uso das tecnologias digitais, há a possibilidade de os líderes eclesiásticos buscarem seus "clientes" religiosos nos infinitos meandros da cultura cibernética, em uma verdadeira busca do cliente com seus interesses não mais coletivos, mas radicalmente centrados em seu âmbito privado.

No escopo da cultura cibernética, há uma maior abertura para um espaço ilimitado, como nunca antes visto, para a proclamação da fé cristã. É possível haver um ambiente que sobrepuje o número de megaigrejas como as de Lakewood, nos Estados Unidos, com seus mais de 40 mil membros, que se reuniam a cada semana antes do período da atual pandemia. ${ }^{35}$ Por certo, não se pode garantir, infelizmente, que essa proclamação não sofra mutações, deturpações e adulterações na mensagem original. É essencial que o querigma ${ }^{36}$ seja compreendido não apenas como uma informação ou objeto de conhecimento ou curiosidade, mas como uma interpelação à liberdade do indivíduo encontrada em Cristo. O objetivo da comunicação do querigma é, segundo Puntel, trazer a experiência da salvação plena e significativa, a qual não pode ser deturpada por uma cultura midiática, que desfaça o sentido originalmente proclamado por Jesus. ${ }^{37}$

Dentro desse cenário atual há a presença da Teologia Prática, a qual não apenas pensa e zela pela vida da igreja, mas também compreende e interpreta a religião que está fora da vida da igreja, na cultura social e pessoal da contemporaneidade. ${ }^{38}$ Atualmente há diversas definições do termo teologia prática, equivocadamente entendida como a prática da teologia, as quais são vistas sob diferentes prismas teórico-metodológicos. Conforme aponta Farris ${ }^{39}$, a Teologia Prática almeja compreender como o Evangelho é interpretado ou expresso na ação. Sumariamente, essa ação é tanto individual quanto institucional. A Teologia Prática é a interpretação de ou a reflexão feita de modo crítico sobre a mensagem de Cristo posta em ação.

Para Deschner ${ }^{40}$, a Teologia Prática tem forte relação com toda a vida de uma congregação - a adoração, a solidariedade e o serviço, isto é, com o receber, o ser e

${ }^{33}$ BERGER, Peter L. O dossel sagrado: elementos para uma teoria sociológica da religião. Trad. José Carlos Barcellos. São Paulo: Paulinas, 1985. p. 370.

${ }^{34}$ FEITOSA, Darlyson. A autoridade do texto bíblico e a privatização da religião. Implicações na perspectiva urbana. Fragmentos de cultura, Goiânia, v. 19, n. 2, p. 147-159, 2009.

${ }^{35}$ CIO INSIGHT, Megachurch-megatech, the voice of the CIO Community. Disponível em: $<$ https://www. cioinsight.com/c/a/Trends/Megachurch-Megatech>. Acesso em: 15 maio 2020.

${ }^{36} \mathrm{O}$ termo querigma refere-se, de maneira panorâmica e sucinta, ao primeiro anúncio às pessoas que nunca ouviram o Evangelho e àqueles cristãos que carecem de uma formação cristã essencial que lhes permitam viver conforme a fé (PUNTEL, 2010).

37 ANDREOLLA, 2012, p. 13.

${ }^{38}$ GRÄB, Wilhelm. Sinn fürs Unendliche: Religion in der Mediengesellschaft. Gütersloh: Chr. Kaiser; Gütersloher Verlag, 2002.

${ }^{39}$ FARRIS, James. O que é Teologia Prática? Revista Caminhando: Revista da Faculdade de Teologia da Igreja Metodista, v. 6, n. 1, p. 57-68, 2001.

40 DESCHNER, 1981, p. 21. 
o agir. Onde há a presença do ser humano, ali estará a igreja com uma missão para ministrar e a eles influenciar, uma vez que a igreja não se encontra, similarmente, isolada das realidades culturais. $\mathrm{O}$ divino e o cultural interconectam-se, estabelecendo diálogos, discussões e aprendizados em ambos os polos.

Deschner ${ }^{41}$ também afirma que a Teologia Prática é a autocrítica e a projeção da igreja concernentes a como ela se entende, ordena, se manifesta e integra a vida atual da congregação, da solidariedade e do serviço do povo de Deus em seus diversos contextos locais. Em suma, uma das tarefas principais da Teologia Prática é examinar a relação entre a igreja e seus contextos vividos, trazendo, no tanto quanto for possível, uma libertação ou transformação do mundo ${ }^{42}$ pelos valores intrinsicamente divinos explicitados pelo amor, a empatia, a solidariedade, o altruísmo, entre outros, sem deixar de levar em crítica consideração e reflexão as consequências de quaisquer ações no âmbito social.

Dito isso, passemos à seção metodológica, de modo a alinhar o que foi dito anteriormente no cabide teórico à presente pesquisa.

\section{Material e métodos}

A presente pesquisa foi realizada sob viés bibliográfico, seguindo uma abordagem qualitativa ${ }^{43}$ sobre o problema pesquisado, explicativa em seus objetivos e compreendida como pesquisa de revisão bibliográfica em seus procedimentos técnicos. ${ }^{44}$ Os instrumentos de coleta de dados basearam-se na coleta bibliográfica de artigos científicos nas áreas da informática, da filosofia da tecnologia e na Teologia Prática, por meio da leitura crítica de textos acadêmicos (artigos, dissertações e teses) concernentes ao assunto com interface entre a teologia e a tecnologia bem como do objeto de pesquisa, isto é, a notícia do website BBC Brasil, publicada no mês de março de 2020 .

Por conta disso, elencam-se as seguintes perguntas nesta pesquisa: como ocorre a busca por Deus diante do cenário de pandemia global em detrimento da Covid-19? Como as tecnologias digitais podem (não) auxiliar na busca por Deus diante do atual cenário contemporâneo de pandemia? Dito isso, busca-se aqui sumariamente investigar a importância das tecnologias digitais dentro dos elementos axiológicos da prática religiosa. Há também o objetivo de similarmente revisar os estudos atuais sobre a interface entre a teologia e as tecnologias, delimitar as diferentes maneiras de utilização da tecnologia para o desenvolvimento e manutenção da fé. Adicionalmente, intenta-se compreender como as tecnologias podem auxiliar na propagação da men-

${ }^{41}$ DESCHNER, 1981, p. 21.

42 WARFORD, Malcolm (Ed.). Practical Wisdom on Theological Teaching and Learning. New York: Peter Lang, 2004.

${ }^{43}$ MARTIN, Bauer; GASKELL, George. Pesquisa qualitativa com o texto, imagem e som. Petrópolis: Vozes, 2008.

44 JOHNSON, Burke; CHRISTENSEN, Larry. Educational Research: Quantitative, Qualitative, and Mixed Approaches. Fifth edition. SAGE Publications, 2013. 
sagem da fé em diferentes contextos religiosos diante do atual cenário da pandemia do coronavírus.

Para tanto, será feita uma análise sucinta, de acordo com o referencial teórico panoramicamente até aqui apresentado, de uma matéria publicada pelo jornal BBC Brasil $^{45}$, de maneira a delimitar diferentes percepções sobre o uso das tecnologias digitais dentro de diferentes contextos religiosos. Mais precisamente, a notícia foi publicada no dia 17 de março de 2020, logo no início da pandemia no Brasil. A notícia, denominada "De cultos online a 'não leia notícias sobre pandemia': como as religiões estão lidando com o coronavírus no Brasil", foi escrita pelo jornalista Leandro Machado e ainda se encontra disponível e acessível a qualquer pessoa.

Passa-se, destarte, à análise e discussão da reportagem.

\section{Dados da pesquisa}

A notícia inicia explanando como a preocupação com a nova Covid-19 também conseguiu alcançar os templos religiosos brasileiros, expondo o fato de igrejas evangélicas e mesquitas suspenderem seus cultos e celebrações por tempo indeterminado. Isso fora determinado a fim de se evitar a aglomeração e uma possível transmissão do vírus entre os próprios fiéis, como foi, segundo o jornalista, o episódio que ocorreu na igreja de Shinchonji, na Coreia do Sul.

Porém o jornalista também apresenta brevemente como alguns líderes religiosos, fazendo alusão nada inocente, inclusive, a uma imagem do pastor Silas Malafaia, fizeram questão de inicialmente não fechar as portas das igrejas, haja vista que isso poderia causar sérios danos a suas congregações. O jornalista posteriormente apresenta alguns dados, bem como números de pessoas atingidas pelo vírus e as diferentes maneiras como o vírus pode ser transmitido. O jornalista também concatena a comparação da igreja com outros locais que também podem se tornar fortes aliados para transmissão em massa do vírus, haja vista pelo grande número de aglomerações recorrentes em instâncias como jogos esportivos, protestos, festas, entre outros. Novamente a igreja Jesus de Shinchonji, cuja seita dedica a ideia de que Lee Man-hee seria a segunda encarnação de Cristo, é mencionada como um exemplo negativo em proliferar o vírus para uma parcela significativa da população.

Posteriormente o jornalista apresenta uma atitude positiva advinda do pastor Ed. René Kivitz, pastor da Igreja Batista da Água Branca, localizada na zona oeste de São Paulo. Conforme o pastor, ele resolveu se juntar a esse esforço mundial de contenção da disseminação do coronavírus, de maneira que os cultos de domingo, com antiga grande concentração de fiéis, foram transmitidos ao vivo pela internet. $\mathrm{O}$ jornalista aponta também o exemplo da Comunidade da Vila, uma igreja evangélica da zona oeste paulistana, com três cultos de domingo, sem a presença de seus fiéis,

${ }^{45}$ MACHADO, Leandro. De cultos online a 'não leia noticias sobre pandemia': como as religiões estão lidando com o coronavírus no Brasil, 2020. Disponível em: <https://www.bbc.com/portuguese/ brasil-51920196>. Acesso em: 10 maio 2020. 
que foram transmitidos pelo próprio aplicativo da igreja. O pastor Marcos Botelho da igreja Comunidade da Vila afirmou em vídeo sobre a pandemia que irá manter sua programação, afirmando a seus irmãos e irmãs na fé: "Vocês não precisam estar junto, porque estamos tentando evitar aglomerações", assim como "Não queremos criar pânico. Acreditamos que Deus está no controle de todas as coisas, mas queremos ajudar o Brasil a não espalhar o vírus e não ocupar nossos leitos de hospitais. Nos vemos online" 46 .

O autor da matéria apresenta o caso da Mesquita Brasil, a qual também cancelou suas orações em congregações, evitando a aglomeração dos fiéis. Até aquela data, o xeique Mohamed al Bukai não havia decidido o que fazer em face da pandemia. Algumas sinagogas em São Paulo também suspenderam as atividades, apesar de haver algumas unidades que mantiveram os cultos em áreas abertas, como em grandes jardins. Terreiros de umbanda também passaram pelo mesmo desafio, com atividades igualmente suspensas majoritariamente em muitos locais, conforme aponta o Pai Engels de Xangô.

Conforme aponta o pastor batista Levi Araújo na entrevista, torna-se importante que as denominações religiosas se posicionem com o propósito de proteger seus fiéis e, consequentemente, o resto da população. O pastor Araújo também aponta que, independentemente de qual for a religião, a situação do coronavírus apontará quem são os fanáticos e quem são os oportunistas, dos quais pensam apenas em dinheiro. Esses, de acordo com Araújo, irão continuar a promover a aglomeração de pessoas dentro das igrejas. Araújo também afirmou que "os religiosos de bom senso vão seguir as orientações da Organização Mundial de Saúde e das autoridades de saúde ${ }^{47}$ ", uma vez que Araújo também aderiu às plataformas on-line para realizar os cultos.

Na última parte da matéria, o jornalista apresenta o embate entre alguns líderes da igreja católica e líderes evangélicos, com igrejas como o Santuário Nacional de Aparecida fechando suas portas para a realização de missas. Em uma diocese de São Paulo, os fiéis foram direcionados a evitar o contato físico, sobretudo na saudação de paz e na oração do Pai-Nosso. O jornalista também relata que igrejas como Sara Nossa Terra, Mundial do Poder de Deus e a Renascer em Cristo mantiveram seus cultos. O pastor Silas Malafaia é apresentado como um exemplo de alguém que não iria fechar a igreja. Em suas palavras: "Não vou fechar a igreja coisíssima nenhuma. Se amanhã os governos disserem que vão impedir transporte público, fechar mercados, fechar todas as lojas. Como pastor, acredito que a igreja tem que ser o último reduto de esperança para o povo"48. Afirmou ainda que, se tudo for fechado, a igreja precisa estar aberta, ainda que seja uma medida drástica.

O missionário R. R. Soares, da Igreja Internacional da Graça de Deus, afirmou que a população não precisa temer de jeito algum o coronavírus. Esse alegou que “já houve outras ameaças no meio da humanidade. A profecia, lá no Apocalipse, diz

\footnotetext{
46 MACHADO, 2020.

${ }^{47}$ MACHADO, 2020.

${ }^{48}$ MACHADO, 2020.
} 
que vai chegar um tempo em que uma terça parte das pessoas vai morrer, mas ainda não estamos nessa época" ${ }^{49}$. Por último, é apresentada a fala do bispo Edir Macedo, da Igreja Universal do Reino de Deus, que pediu aos fiéis para que não lessem notícias sobre o coronavírus. Em um vídeo na rede social Instagram, Macedo afirma que "quem anda pela fé anda pela frente. Quando você vê no noticiário 'morreu fulano, beltrano teve coronavírus', não olhe para isso, não leia essas notícias”. Ele prossegue dizendo que "ao invés de você ler essas notícias que falam de morte e de quarentena, da epidemia e pandemia, olhe para a Palavra de Deus e tome sua fé na Palavra de Deus, porque essa, sim, faz você ficar imune a qualquer praga e a qualquer vírus, inclusive o coronavírus". Orações com a imposição de mãos devem ser evitadas, recomenda o bispo Edir Macedo.

\section{Análise e discussão dos dados}

Nota-se que o teor da notícia é aparentemente descritivo, uma vez que apresenta os relatos de grandes e conhecidas denominações cristãs, em especial as evangélicas, no cenário brasileiro. Percebe-se dentro da reportagem como as diferentes igrejas e religiões estão passando por um período em que a cibercultura ${ }^{50}$ parece estar recentemente entrando nas denominações cristãs, uma vez que ainda há a presença de líderes como Malafaia, Macedo e Soares do lado cristão, bem como Bukai, Pai Engels e a Federação Israelita enfrentando grandes lutas para o uso das tecnologias. Nota-se que esses líderes perfazem os usuários imigrantes digitais ${ }^{51}$, os quais, como supracitado, são resistentes quanto ao uso e à vivência dentro do ciberespaço, haja vista a complexidade e diferença que esses novos meios de se viver e mover no mundo virtual permitem a seus residentes.

A falta da presença dos fiéis nos seus templos religiosos, até onde se pode inferir, denotaria a perda da fé ou a supressão da presença mais ativa desses. Conforme apontam Deschner ${ }^{52}$ e Farris ${ }^{53}$, a igreja não está isolada de todo seu contexto social e cultural nela envolto e, caso haja alguma mudança em alguma esfera da sociedade, como essa ocorrida drasticamente por conta do coronavírus, a igreja também será influenciada. Isso ocorre por conta da interconexão que a igreja estabelece com seu entorno sociocultural.

No entanto, levanta-se um questionamento neste momento. Até que ponto a influência da igreja é desfalecida para poder continuar a proclamação do querigma ${ }^{54}$, mesmo quando as bases comunicacionais e locais, de aglomeração, a seus fiéis são minimizadas? Como no caso relatado anteriormente sobre a megaigreja de Lakewood, a qual conta ainda com mais de 40 mil membros, e a qual está ativamente realizando dife-

\footnotetext{
49 MACHADO, 2020.

${ }^{50}$ LÉVY, 1999, p. 117.

51 PRENSKY, 2010, p. 123.

52 DESCHNER, 1981, p. 22.

${ }_{53}$ FARRIS, 2001, p. 59.

54 ANDREOLLA, 2012.
} 
rentes cultos e celebrações on-line a fim de alimentar, nutrir e compartilhar sua fé com uma comunidade agora não mais limitada apenas a quatro paredes de sua denominação, como poderia se comparar as igrejas brasileiras com essa americana? Espera-se que um desastre como o que ocorreu na denominação religiosa coreana não ocorra no cenário brasileiro. Estamos passando por diferentes ondas neste momento na história, conforme aponta Puntel ${ }^{55}$, o que trará consigo diferentes desfechos e atitudes.

Percebem-se, similarmente, atitudes diferentes tomadas por líderes como Kivitz e Marcos Botelho, os quais, em diferentes localidades, assumem posições iguais quanto à contenção da disseminação do vírus e à proteção dos fiéis em suas denominações. Tal ação revela a aceitação do uso de plataformas e mídias digitais para a realização de celebrações litúrgicas. Isso sugere possivelmente que tais líderes representem o que denominamos nativos digitais, os quais estão abertos para novos desafios e conseguem se adaptar apesar das limitações externas possíveis. ${ }^{56} \mathrm{Um}$ ponto a ser ressaltado aqui diz respeito à credibilidade que os líderes religiosos parecem dar ao ciberespaço. ${ }^{57}$ Parece haver uma certa descrença quanto à potencialidade das tecnologias digitais, sobre o que elas podem trazer de possíveis (des)vantagens àqueles que as utilizam. Conforme visto anteriormente, as tecnologias digitais oferecem uma gama aparentemente ilimitada de ferramentas e seu alcance pode chegar não apenas à comunidade local ${ }^{58}$, trazendo a oportunidade de a igreja poder evangelizar até mesmo em locais que não conseguiria alcançar, caso estivesse apenas realizando cultos no mundo off-line.

Outro aspecto também presente na matéria concerne à negação de Malafaia e Edir Macedo sobre o fato de a pandemia estar, de fato, ocorrendo. O primeiro líder faz uso de sua autoridade eclesiástica ao dizer que não fecharia a igreja por motivo ou "coisíssima" nenhuma, já que acredita que a igreja é o "último reduto" da sociedade para a esperança daquele que se encontra perdido. Já Edir Macedo apresenta a seus irmãos de fé que esses devem estar aquém dos fatos relatados nos noticiários, uma vez que eles precisavam ter mais Coronafé do que a Coronadúvida. Tais atitudes, embora possam ser fundamentadas em certo medo de se perder a frequência assídua dos fiéis, talvez abarque o silogismo de que "não frequentar o templo signifique perda da fé".

A pergunta que nasce no meio desse silogismo é: até que ponto se pode dizer que os fiéis podem perder sua fé pelo fato de modificarem sua maneira de estar agora participando de cultos ou celebrações religiosas dentro do ciberespaço on-line? A não frequência a templos religiosos implica necessariamente uma perda da fé? Adicionalmente, estão esses líderes religiosos preocupados mais com a fé ou com a saúde desses fiéis frequentadores desses templos? Até que ponto estão dependentes de seus líderes religiosos aqueles que estão nos templos para buscar a face de Deus?

A igreja está preparada para alcançar um diferente próximo que antes não conseguia perceber em sua realidade local, como na parábola do bom samaritano (Lucas

\footnotetext{
55 PUNTEL, 2017, p. 11.

56 PRENSKY, 2010, p. 121.

57 SPADARO, 2012, p. 13.

58 ANDREOLLA, 2012.
} 
10.25-37). Haveria algo dentro da realidade religiosa que poderia descredibilizar a verdade do Evangelho ao ser transmitido on-line? Haveria dentro desse cenário a perda do cliente fiel que faz uso dos bens de consumo dentro do mercado religioso ${ }^{59}$ Aliás, estaria a igreja disposta a receber críticas assim como elogios ou palavras de conforto, mesmo em tempos críticos de pandemia e possivelmente perder seus clientes fiéis diante do constante fenômeno de privatização da religião? ${ }^{60}$ Para saber como essas perguntas serão respondidas, basta apenas "nos ver on-line" nos próximos meses, como afirmou o líder Marcos Botelho.

De fato, quanto mais a igreja puder se expor no ciberespaço, será possível ver que a sua materialidade e princípios poderão alcançar não apenas uma credibilidade maior, bem como uma abrangência exponencialmente maior em relação ao momento anterior à epidemia. As igrejas, de certo modo, estão sendo expostas na vitrine e sábios são aqueles que conseguem fazer uso das oportunidades (apesar das dificuldades para essas existirem) para que a mensagem do Evangelho continue sendo compartilhada. Conforme apontou o pastor Levi Araújo, dentro desse cenário será possível visualizar quem possivelmente são os líderes oportunistas, os quais pensam apenas no dinheiro advindo da obra realizada e aqueles aliados à mensagem evangelística.

Pergunta-se, aqui, até que ponto a crença de que Deus poderá suprir todas as nossas necessidades, conforme apontava o apóstolo Paulo (Filipenses 4.19) existe no coração de tais líderes possivelmente oportunistas. Nada passa despercebido aos olhos de Deus (Provérbios 15.3). É tempo de se readaptar, tempo de inovar, como o fora em diferentes épocas da igreja na história da humanidade. ${ }^{61}$ Outro desafio imposto às igrejas está no fato delas precisarem trabalhar com temas complexos e que reivindiquem uma frequência contínua dos fiéis para poderem continuar crescendo na fé e em suas vidas com Deus. É essencial que a igreja consiga se reorganizar para tanto garantir quanto manter o desenvolvimento espiritual de seus frequentadores, sabendo que o Corpo de Cristo (a igreja) ainda está vivo, embora presencialmente ou materialmente distante. Levanta-se, aqui, destarte, o perigo de a igreja possivelmente trabalhar apenas com o lado emocional (pathos grego), ao invés de suprimir elementos essenciais para o crescimento da fé cristã ${ }^{62}$, tais como a oração, o estudo bíblico e a continuidade da comunidade, dentro de uma liturgia que abarque o culto racional mencionado pelo apóstolo Paulo (Romanos 12.1-2).

Outro aspecto relevante a ser notado na reportagem é o contraste entre a mensagem do bispo Edir Macedo, o qual afirmou a seus irmãos na fé para não assistirem notícias concernentes ao coronavírus, e a atitude da Igreja Universal. Em uma possível atitude de manter-se fiel à leitura da Bíblia, levando-se em conta o papel que essa tem na formação do cristão em seu espectro espiritual, social, emocional, entre outros, o bispo afirmou que os cristãos deveriam apegar-se à palavra de Deus, a fim de que esses vencessem a coronadúvida. Porém, apesar da visão de Macedo, a Igreja

${ }^{59}$ BERGER, 1985, p. 185 .

${ }^{60}$ FEITOSA, 2009, p. 148.

${ }^{61}$ PUNTEL; SBARDELOTTO, 2017, p. 15.

62 ANDREOLLA, 2012, p. 11. 
Universal tomou medidas preventivas para conter a aglomeração e a proliferação do vírus entre os fiéis e a sociedade em geral. Percebe-se, portanto, que a cosmovisão compartilhada por um líder religioso pode não ser seguida pela igreja institucional, demonstrando que as visões eclesiais em uma era de contínuas mudanças nas nuances sociais $^{63}$ podem em muito variar dentro de uma mesma igreja marcada pela Reforma da Informação. ${ }^{64}$

\section{Conclusões preliminares}

O presente artigo trouxe um relevante tema diante da atual pandemia do coronavírus: a atuação, propagação e vivência do Evangelho e de outras crenças religiosas, dentro de um lócus contagioso por conta da Covid-19. Nota-se como as tecnologias digitais trouxeram diferentes oportunidades, trazendo um deslocamento à sociedade em diferentes pontos, inclusive o espiritual. Por conta dessas modificações na engrenagem da sociedade ${ }^{65}$, surgiu com isso uma cibercultura, um ciberespaço, que carrega consigo uma nova maneira de se evangelizar, de se comportar, de se viver tanto no mundo off-line quanto on-line. ${ }^{66}$

Concernente à primeira pergunta de pesquisa, (Como ocorre a busca por Deus diante do cenário de pandemia global em detrimento da Covid-19?), nota-se que essa busca encontra-se consideravelmente influenciada por um cenário cercado pela descrença por parte de líderes religiosos aparentemente mais conhecidos pela mídia, como Silas e Macedo. Há similarmente a presença de líderes religiosos que se adaptam diante dos contrastes atuais, tais como os pastores das denominações batistas. Em relação à segunda pergunta (Como as tecnologias digitais podem (não) auxiliar na busca por Deus diante do atual cenário contemporâneo de pandemia?), nota-se que as tecnologias digitais propiciam não apenas novas maneiras semióticas de se produzir sentido ${ }^{67}$, como também a criação de novos lugares onde a igreja pode atuar ${ }^{68} \mathrm{e}$ espalhar a luz do Evangelho.

A Teologia Prática tem muito para auxiliar nessa área, haja vista que essa pensa e zela pela vida da própria igreja, bem como intenta compreender a religião vivida fora do espaço religioso. ${ }^{69}$ Diferentes maneiras de se viver a fé cristã estão sendo expostas sobre o ser e fazer a igreja dentro da Era das Mídias. ${ }^{70}$ As diferentes visões apresentadas pelos líderes religiosos, às vezes favoráveis a fechar seus locais de realização de cultos, às vezes indo frontalmente contra essa opinião, demonstram uma

\footnotetext{
63 ANDREOLLA, 2012.

${ }^{64}$ PUNTEL; SBARDELOTTO, 2017, p. 15.

65 VOLTI, 2009, p. 50.

66 SBARDELOTTO, 2012.

${ }^{67}$ PAIVA, 2013, p. 22.

${ }^{68}$ SPADARO, 2012.

69 GRÄB, 2002, p. 70.

${ }^{70}$ CASTELLS, 2005.
} 
transição e um conflito de pensamento àqueles que (não) estão abertos ou até mesmo dispostos a se reinventar dentro do atual cenário pandêmico. ${ }^{71}$

O fato é que atualmente há uma outra possibilidade de se apresentar o Evangelho de maneira nunca antes vista, de se criar uma realidade talvez não possível com os recursos antes disponíveis para a propagação da mensagem de Jesus. Adicionalmente, conforme criticamente apontou Spadaro ${ }^{72}$, o ciberespaço apresenta-se não mais como uma ferramenta adicional, mas como um novo espaço frequentado por diferentes religiões e pelos cristãos. Em analogia ao título deste artigo, dentro da ciberteologia, dessa teologia atrelada ao espaço digitalmente construído, o Verbo (João 1.1), representando Jesus, se faz presente não apenas em forma espiritual. O verbo se tornou em BIT.

Em vez de voltarmos à "normalidade" existente (se é que é possível dizer que o que foi vivido anteriormente fora normal) anterior ao coronavírus, por que não podemos nos transformar ou nos reinventar diante desse novo cenário que, apesar de apresentar suas dificuldades, também abre a oportunidade de nos reinventarmos? Estamos vivendo uma "nova normalidade" e cabe àqueles que são fiéis a Cristo o papel de alargar as tendas (Isaías 54.2-3) da igreja, para que seu alcance não seja suprimido, mas maximizado, exteriorizado e alcançado por aqueles que possivelmente vivem na escuridão. Assim, a luz da Palavra (Salmo 119.105) poderá brilhar sobre os corações daqueles que ainda buscam em Jesus a solução para seus maiores problemas no âmago existencial, seja em meio à pandemia ou em momento posterior a esse cenário contagioso contemporâneo.

\section{Referências}

ANDREOLLA, Jurema. A fé cristã na era digital: Diálogo entre a revelação na tecnologia de Bruno Forte e a experiência religiosa na Internet. 2012. Dissertação (Mestrado em Teologia) Pontifícia Universidade Católica do Rio Grande do Sul (PUCRS), Porto Alegre, 2012.

BERGER, Peter L. O dossel sagrado: elementos para uma teoria sociológica da religião. Trad. José Carlos Barcellos. São Paulo: Paulinas, 1985.

BERROCAL, Pablo; RUIZ, Desirée. Emotional Intelligence in Education. Electronic Journal of Research in Educational Psychology, v. 6, n. 15 (2), p. 421-436, 2008.

BRUSTOLIN, Leomar A. Quando Cristo vem... A Parusia na escatologia cristã. São Paulo: Paulus, 2001.

CASTELLS, Manuel. A sociedade em rede. São Paulo: Paz e Terra, 2005.

CIO INSIGHT. Megachurch-megatech, the voice of the CIO Community. Disponível em: $<\mathrm{https} / /$ www.cioinsight.com/c/a/Trends/Megachurch-Megatech>. Acesso em: 15 maio 2020.

COPPE, Moisés Abdon. Ethos Mundial e Nova Criação: um debate necessário para a salvaguarda do planeta Terra. Revista Caminhando, v. 19, n. 1, p. 97-108, 2014.

DESCHNER, John. Preface to Practical Theology. J. Arthur Heck Lectures. United Theological Seminary, p. 21-22 de abril, 1981. Manuscrito não publicado.

${ }^{71}$ ZHOU et al., 2020, p. 25.

72 SPADARO, 2011, p. 12. 
DI FELICE, Massimo. As redes digitais vistas a partir de uma perspectiva reticular. 2011. Disponível em: <http://www.ihu.unisinos.br/entrevistas/500515-pos-complexidade-asredesdigitais-vistas-a-partir-de-uma-perspectiva-reticular-entrevista-especial-commassimo-di-felice> . Acesso em: 20 nov. 2016.

ELLUL, Jacques. La technique ou l'enjeu du siècle. Paris: Économica, 2008.

FARRIS, James. O que é Teologia Prática? Revista Caminhando: Revista da Faculdade de Teologia da Igreja Metodista, v. 6, n. 1, p. 57-68, 2001.

FEENBERG, Andrew. Transforming Technology: a critical theory revisited. New York: Oxford University Press, 2002.

FEITOSA, Darlyson. A autoridade do texto bíblico e a privatização da religião. Implicações na perspectiva urbana. Fragmentos de cultura, Goiânia, v. 19, n. 2, p. 147-159, 2009.

GRÄB, Wilhelm. Sinn fürs Unendliche: Religion in der Mediengesellschaft. Gütersloh: Chr. Kaiser; Gütersloher Verlag, 2002.

JOHNSON, Burke; CHRISTENSEN, Larry. Educational Research: Quantitative, Qualitative, and Mixed Approaches. Fifth edition. SAGE Publications, 2013.

LEITCH, Vincent. Postmodern Theory of Technology: Agendas. Symploke, v. 12, n. 1, p. 209215, 2004.

LÉVY, Pierre. Cibercultura. São Paulo: Editora 34, 1999.

LIBÂNIO, João Batista. A religião no início do milênio. São Paulo: Loyola, 2002.

LIMA, Daniel Barros. Cosmovisão cristã: a transformação da mente cristã na contemporaneidade. Protestantismo em Revista, São Leopoldo, v. 36, p. 48-63, 2015.

LIMA, Claudio Marcio. Informações sobre o novo coronavírus (COVID-19). Radiol Bras, São Paulo, v. 53, n. 2, p. 5-6, 2020.

LITTO, Frederico; FORMIGA, Marcos (Ed.). Educação a distância: o estado da arte. 2. ed. São Paulo: Pearson, 2012.

MACHADO, Leandro. De cultos online a 'não leia notícias sobre pandemia': como as religiões estão lidando com o coronavírus no Brasil, 2020. Disponível em: <https://www.bbc.com/ portuguese/brasil-51920196>. Acesso em: 10 maio 2020.

MARTELLI, Stefano. A religião na sociedade pós-moderna: entre secularização e dessecularização. São Paulo: Paulinas, 1995.

MARTIN, Bauer; GASKELL, George. Pesquisa qualitativa com o texto, imagem e som. Petrópolis: Vozes, 2008.

OLIVEIRA, Márcio Divino. Cuidado pastoral da igreja em tempos de pandemia: Covid-19. Revista Caminhando, v. 25, n. 1, p. 257-276, 2020.

PAIVA, Vera. A formação do professor para uso da tecnologia. In: SILVA, K. A. et al. (Orgs.). A formação de professores de línguas: Novos Olhares. Campinas: Pontes, 2013. v. 2, p. 209-230. PRENSKY, Marc. Teaching digital natives: partnering for real learning. Corwin Edition, 2010. PUNTEL, Joana Teresinha; SBARDELOTTO, Moisés. Da reforma histórica à "reforma digital": desafios teológicos contemporâneos. Estudos Teológicos, São Leopoldo, v. 57, n. 2, p. 350-364, 2017. Comunicação: diálogo dos saberes na cultura midiática. São Paulo: Paulinas, 2010. SBARDELOTTO, Moisés. Deus digital, religiosidade online, fiel conectado: Estudos sobre religião e internet. Cadernos Teologia Pública, São Leopoldo, Ano IX, n. 70, 2012. Disponível em: $<$ http://www.ihu.unisinos.br/images/stories/cadernos/teopublica/070cadernosteologiapubl ica.pdf $>$. Acesso em: 29 out. 2018.

SINGH, Paul. Use of science and technology as a tool of social change. International Journal of Academic Research and Development, v. 2, n. 1, p. 124-127, 2017. 
SPADARO, Antonio. Spiritualità ed Elementi per una Teologia della Comunicazione in Rete. In: Seminário de Comunicação para os Bispos do Brasil (SECOBB), 2011, Rio de Janeiro. Anais. Brasília: CNBB, 2011.

Ciberteologia: pensar o Cristianismo em tempos de rede. São Paulo: Paulinas, 2012.

TAVARES, Cássia Quelho. Dimensões do cuidado na perspectiva da espiritualidade durante a pandemia pelo novo coronavírus (COVID-19). J Health NPEPS, v. 5, n. 1, p. 1-4, 2020.

THEOBALD, Cristoph. A exortação apostólica Evangelii Gaudium. Cadernos Teologia Pública, edição 104, v. 12, 2016.

THORNBURY, Scott. How to Teach Speaking. England: Pearson Education Limited, 2002.

TONNIES, Ferdinand. Community and Society - Gemeinschaft and Gesellschaft. New Brunswick: N J Transaction books, 1988.

VOLTI, Rudi. Society and Technological Change. 7th Ed. New York: Worth, 2009.

WARFORD, Malcolm (Ed.). Practical Wisdom on Theological Teaching and Learning. New York: Peter Lang, 2004.

ZHOU, Longjung et al. 'School's Out, But Class' On', The Largest Online Education in the World Today: Taking China's Practical Exploration During The COVID-19 Epidemic Prevention and Control as an Example of Best Evidence. Chinese Education, v. 4, n. 2, p. 501-519, 2020. 